\title{
O uso da Informação sobre o País de Origem de Produtos Brasileiros como Fonte de Vantagem Competitiva nos Mercados Externos ${ }^{\mathrm{I}}$
}

\section{THE USE OF BRAZILIAN PRODUCTS' COUNTRY OF ORIGIN INFORMATION AS A SOURCE OF COMPETITIVE ADVANTAGE IN EXTERNAL MARKETS}

JANAINA DE MOURA ENGRACIA GIRALDI Mestranda em Administração pela Faculdade de Economia, Administração e Contabilidade - Universidade de São Paulo. Rua Clemente Ferreira, 955 - Ribeirão Preto - SP - CEP 14.020-4 10 E-mail: janainagiraldi@fearp.usp.br

DIRCEU TORNAVOI DE CARVALHO Professor doutor da Faculdade de Economia, Administração e Contabilidade de Ribeirão Preto - Universidade de São Paulo. Av. dos Bandeirantes, 3900 - Bloco A, sala 6BRibeirão Preto - SP - CEP 14.040-900 E-mail: tornavoi@usp.br

I Este trabalho recebeu o apoio financeiro da Fapesp. 


\section{RESUMO}

Em um mercado global cada vez mais competitivo, torna-se cada vez mais difícil o estabelecimento de uma vantagem competitiva. A noção de que um desempenho superior requer que uma empresa adquira e sustente uma vantagem sobre a concorrência é central para o pensamento estratégico contemporâneo. Um atributo que oferece potencial para vantagem competitiva, tanto no mercado interno quanto no externo, é o país de origem do produto. Em geral, considera-se que o país de origem influencia as avaliações de produtos pelo consumidor e as suas decisões de compra. Como as organizações lidam com recursos limitados, elas precisam tentar desenvolver estratégias apropriadas à sua base de recursos. Nesse sentido, o presente artigo investiga a possibilidade de utilizar a informação do país de origem de produtos brasileiros como uma fonte de vantagem competitiva para as empresas brasileiras operantes no mercado externo. Um importante empecilho para essa estratégia deve-se à imagem do Brasil no exterior, que é principalmente associada a algumas habilidades esportivas ou criativas, não sendo atribuído quase nenhum significado ou importância ao Brasil enquanto provedor de itens de maior conteúdo tecnológico.

\section{PALAVRAS-CHAVE}

Vantagem competitiva; País de origem; Estratégia.

\section{ABSTRACT}

In an increasingly competitive global market, it has become harder to establish a competitive advantage. The notion that superior performance demands that a firm acquires and retains an advantage over competition is central to the contemporary strategic thinking. An attribute that offers potential to become a competitive advantage, both in domestic and external markets, is the product's country of origin. In general, it is considered that the country of origin influences the products' evaluations by the consumer and his or her purchase behavior. Since the organizations deal with limited 
resources, they need to try to develop strategies that are appropriate for their resource base. In this sense, the present paper investigates the possibility to use the country of origin information of Brazilian products as a source of competitive advantage for the exporting Brazilian firms. An important obstacle for this strategy is related to Brazil's image abroad, which is mainly associated to some sports or creative skills, not being given almost any meaning or importance to Brazil as a provider of items of more technological content.

\section{KEYWORDS}

Competitive advantage; Country of origin; Strategy.

\section{INTRODUÇ ̃̃O}

A fragmentação dos mercados em segmentos cada vez mais estreitos de clientes e a globalização crescente da concorrência têm sido as forças convergentes que favorecem uma nova perspectiva sobre as estratégias competitivas (DAY, I990). As tecnologias de informação tornam indistinguíveis as tradicionais linhas de demarcação entre mercados e empresas, ao mesmo tempo em que aceleram o ritmo das decisões. Os ciclos de vida dos produtos estão sendo encurtados pelas mudanças tecnológicas, e os clientes vêm exigindo níveis cada vez mais elevados de atendimento e qualidade. Os novos arranjos organizacionais, nos quais redes e parcerias entre fornecedores, canais de comercialização e clientes são criados, também contribuem para o aumento da pressão sobre as empresas.

Além disso, a rápida globalização dos mercados provocou um crescimento sem precedentes no comércio internacional nas últimas décadas. O tempo e a distância estão encurtando-se rapidamente com o advento, nos últimos anos, de comunicações, transportes e fluxos financeiros cada vez mais rápidos. Com isso, ocorre um aumento na competição global; empresas domésticas que nunca pensaram na existência de concorrentes estrangeiros os encontram, repentinamente, dentro de seus próprios mercados. Para defender suas posições, as empresas devem aprender como entrar em mercados estrangeiros e aumentar sua competitividade global (KOTLER, I995). Para Kotler (I995), quanto maior a demora das empresas em tomar providências em direção à internacionalização, mais elas correrão o risco de ficar de fora de mercados promissores, como a Europa Ocidental, Europa Oriental, Extremo Oriente e outros.

Considerando o atual cenário turbulento, as empresas devem desenvolver suas respostas ao ambiente, em forma de estratégias que especifiquem como pretendem competir nos mercados escolhidos. Porter (I986) afirma que cada 
empresa que compete em uma indústria possui uma estratégia competitiva, seja ela explícita ou implícita. De uma forma geral, a superioridade competitiva de uma empresa refere-se ao que pode ser observado no mercado (do ponto de vista dos clientes ou dos concorrentes): valor superior proporcionado aos clientes ou custo entregue o mais baixo possível.

A literatura existente sobre vantagem competitiva deixa claro que a obtenção de uma vantagem competitiva envolve, invariavelmente, a posse de uma característica única que não pode ser adquirida ou copiada pelos concorrentes (BAKER e BALLINGTON, 2002). Os atributos físicos e tangíveis são relativamente fáceis de copiar. Conseqüentemente, os consumidores precisam procurar por outras evidências para serem capazes de separar conscientemente as alternativas concorrentes.

Nesse sentido, um atributo que oferece o potencial para conferir uma vantagem competitiva é a imagem do país de origem (BAKER e BALLINGTON, 2002). A imagem do país de origem pode se tornar uma importante ferramenta, exprimindo um componente emocional e intangível que pode afetar as decisões de investimento. Portanto, esse atributo deveria receber uma atenção especial dos tomadores de decisão com relação às estratégias de exportação de um país, apesar dos altos custos e riscos envolvidos.

\section{PROBLemA E MÉTOdO dE PESQUISA}

O presente artigo possui caráter essencialmente teórico. O problema a ser investigado é: a informação acerca do país de origem de produtos brasileiros pode ser utilizada como fonte de vantagem competitiva nos mercados externos? Para responder a essa questão, inicia-se o trabalho com uma breve revisão da literatura acerca dos efeitos causados pelo país de origem dos produtos. A seguir, as fontes de vantagem competitiva para uma empresa são apresentadas. Por fim, são destacadas as conclusões, ressaltando a importância da melhoria da imagem do Brasil como instrumento de agregação de valor às exportações brasileiras e fonte de vantagem competitiva para as empresas atuantes no mercado externo. Por se tratar de um trabalho de cunho teórico, o método de pesquisa empregado foi o de uma pesquisa exploratória, utilizando a análise de dados secundários (MCDANIEL e GATES, I996). Os levantamentos em fontes secundárias envolveram levantamentos bibliográficos, como livros e pesquisas já efetuadas sobre o tema em estudo. 


\section{IMAGEM DE UM PAÍS}

A fim de compreender as relações entre vantagem competitiva e imagem do país de origem, em primeiro lugar é necessário definir esses termos. Esta seção trata da definição do termo "imagem do país de origem". Porém, é necessário também conceituar imagem de um produto e imagem organizacional, de forma que se percebam as semelhanças com o conceito de imagem de um país. Segundo Schiffman e Kanuk (I997), os consumidores possuem um número de percepções duradouras, ou imagens, que são particularmente importantes para o estudo do seu comportamento. A imagem de um produto ou marca refere-se ao conjunto de associações relacionadas a esse produto ou marca que o consumidor armazena em sua memória (ENGEL; BLACKWELL; MINIARD, I995). Uma imagem positiva está associada à lealdade do consumidor, às crenças acerca de valores positivos do produto ou marca, e à disposição de procurar pelo produto ou marca nas lojas. Além disso, uma imagem positiva auxilia o consumidor a estar favoravelmente inclinado às promoções desse produto ou marca e a resistir aos ataques da concorrência (SCHIFFMAN e KANUK, I997).

Os consumidores também podem estender as suas imagens para as organizações. Os fabricantes que possuem uma imagem favorável geralmente têm seus novos produtos aceitos de uma forma mais rápida do que os fabricantes que possuem uma imagem menos favorável ou mesmo neutra. Por isso, muitas empresas utilizam propaganda e patrocínio de eventos na comunidade para melhorar as suas imagens. Verifica-se, portanto, que os produtos, as marcas e as organizações possuem valores simbólicos para os indivíduos, que os avaliam com base na consistência em relação a suas próprias auto-imagens. Os consumidores procuram preservar ou melhorar as suas auto-imagens com a compra de produtos considerados congruentes com essas auto-imagens, evitando aqueles produtos que não o sejam (SCHIFFMAN e KANUK, I997).

Fazendo-se uma analogia com a definição de imagem de produto e marca apresentada por Engel, Blackwell e Miniard (I995), pode-se dizer que a imagem de um país é o conjunto de associações existentes entre o país e outras informações armazenadas na memória do consumidor. Mas, para Ayrosa (2000), a definição de imagem de país não tem sido clara na literatura, com muitos autores confundindo os conceitos de imagem de um país específico e imagem dos produtos originados nesse país. Um exemplo dessa confusão é a definição de Han (I988), que considera a imagem do país como a diferença de qualidade percebida entre produtos domésticos e estrangeiros. Na mesma linha, Nagashima (I970) descreveu a imagem de um país como a representação, a reputação, o estereótipo que os homens de negócios e os consumidores colocam nos produtos de um país específico. Essa imagem é criada por variáveis como: produtos representativos, características nacionais, panorama econômico e político, história e tradições. 
Outros autores consideram a imagem de um país distinta da imagem dos produtos fabricados nesse país. Papadopoulos (I993), por exemplo, considera a imagem de um país como sendo a imagem acerca de um país e os pensamentos criados por essas imagens nas mentes dos consumidores. Da mesma forma, Verlegh e Steenkamp (I999) indicam que a imagem de um país refere-se às representações mentais acerca das pessoas, produtos, cultura e símbolos nacionais desse país. Segundo os autores, as imagens de países possuem estereótipos culturais amplamente compartilhados, que persistem mesmo quando os consumidores realmente experimentam os produtos do país. As imagens de países também contêm impressões gerais acerca dos países e crenças idiossincráticas acerca dos produtos do país, as quais os consumidores formaram com a experiência direta ou indireta com o produto.

As imagens formadas pelos consumidores acerca de um país são baseadas nas inferências feitas por meio de estímulos de marketing e do ambiente. Essas inferências caracterizam uma das formas pelas quais os consumidores interpretam uma informação: categorização e inferência (ASSAEL, I995). A categorização envolve a tendência de alocar a informação em categorias lógicas, auxiliando o consumidor a processar a informação conhecida de forma rápida e eficiente, e também a classificar uma nova informação. Por sua vez, a inferência envolve o desenvolvimento de uma associação entre dois estímulos.

As inferências que os consumidores fazem acerca de um país relacionam-se com as crenças que esses consumidores possuem acerca do país, formadas pelas associações passadas. Tais inferências são também baseadas nos sinais e símbolos associados com o país. A imagem formada do país é, portanto, a percepção total de um país que os consumidores possuem, ao processar a informação advinda de várias fontes através do tempo. A psicologia Gestalt sugere que a formação de uma imagem é um processo natural de desenvolvimento da percepção total de um objeto (ASSAEL, I995). Como o país de origem pode atuar como um estereótipo (NAGASHIMA, I970), ele ou pode refletir as representações mentais da realidade, ou pode não corresponder à realidade, sendo o resultado de "associações ilusórias" ou de processos de inferências incorretos (BALABANIS; MUELLER; MELEWAR, 2002).

\section{EFEITO PAÍS DE ORIGEM}

A imagem de um país afeta diretamente as avaliações que os consumidores fazem a respeito dos produtos fabricados nesse país, fenômeno conhecido como "efeito país de origem". O efeito país de origem refere-se à influência da informação sobre o país de origem nas atitudes dos consumidores com relação aos produtos advindos desse país, nas crenças acerca os atributos desses produtos, ou nas atitudes e comportamentos relacionados à compra desses produtos (AYROSA, 2000). 
Desde o primeiro artigo sobre esses efeitos em I965, mais de 300 trabalhos já foram publicados. Para Ayrosa (2000), as formas de se comunicar a informação acerca do país de origem incluem: o rótulo "fabricado em" ("made in"), a sugestão direta por meio da marca ou do nome da empresa (por exemplo, British Airways, Ibéria), a sugestão indireta por meio da sonorização ou da ortografia da marca ou do nome da empresa (por exemplo, Ferrari, Matsushita, Olivetti, Renault), e a indicação ou sugestão pela embalagem do produto (por exemplo, cerveja Fosters, Reebok).

Os estudos sobre os efeitos do país de origem têm procurado identificar processos que possam ajudar a explicar como o país de origem influencia a avaliação de um produto. Em seu trabalho, Ayrosa (2000) descreveu os principais resultados da área de pesquisa sobre país de origem. Os seguintes tópicos foram abordados: a existência de efeitos derivados do país de origem, a existência do viés favorecendo as atitudes com relação a países mais desenvolvidos, o viés dos pesquisadores com relação a determinados países, as interações entre a informação sobre o país de origem e marca, preço e características demográficas. O Quadro I apresenta os resultados citados, com exceção dos referentes às interações entre país de origem e características demográficas do consumidor, as quais serão vistas posteriormente.

\section{QUADRO I}

PRINCIPAIS RESULTADOS DA AREA DE

PESQUISA SOBRE PAÍS DE ORIGEM

\begin{tabular}{l|l}
\hline \multicolumn{1}{c|}{ Resultado } & \multicolumn{1}{c}{ Descrição } \\
\hline $\begin{array}{l}\text { O efeito país de } \\
\text { origem existe. }\end{array}$ & $\begin{array}{l}\text { De acordo com os resultados de pesquisas elaboradas durante 31 anos, por vários } \\
\text { autores, os efeitos do país de origem nas avaliações de produtos realmente existem } \\
\text { para uma variedade de categorias de produtos e diferentes tipos de consumidores. }\end{array}$ \\
\hline $\begin{array}{l}\text { Viés favorecendo } \\
\text { os países mais } \\
\text { desenvolvidos. }\end{array}$ & $\begin{array}{l}\text { Países mais desenvolvidos são percebidos como "melhores" países de origem do que } \\
\text { países menos desenvolvidos. }\end{array}$ \\
\hline $\begin{array}{l}\text { Viés dos pesquisadores. } \\
\text { A diversidade de países usados em experimentos é surpreendentemente pequena, } \\
\text { o que torna a generalização dos resultados muito difíil. Países como EUA, Japão e } \\
\text { Alemanha são os mais mencionados como tendo "imagem favorável", enquanto } \\
\text { México, Tailândia e Taiwan são muito populares como "imagem desfavorável". }\end{array}$ \\
\hline $\begin{array}{l}\text { Interações entre país } \\
\text { de origem e outros } \\
\text { atributos do produto. }\end{array}$ & $\begin{array}{l}\text { Marca: uma marca bem conhecida pode compensar os efeitos negativos advindos de } \\
\text { um país de origem desfavorável para algumas categorias de produtos. A familiaridade } \\
\text { e a percepção de risco devem influenciar as interações entre marca e país de origem. } \\
\text { Preço: efeitos negativos advindos de imagens desfavoráveis de países podem ser } \\
\text { compensados por descontos nos preços dos produtos. } \\
\text { Outros atributos: garantia, força de vendas e imagem do varejista apresentam efeitos } \\
\text { semelhantes aos da marca e preço. }\end{array}$
\end{tabular}

Fonte: Adaptado de Ayrosa (2000). 
Para Engel, Blackwell e Miniard (I995), o país de origem atua como um critério de avaliação de produtos. Os critérios utilizados pelos consumidores são nada mais que dimensões ou atributos usados no julgamento das alternativas para uma compra específica. Os critérios de avaliação podem vir em várias formas, como segurança, confiabilidade, preço, marca, país de origem, garantia e atributos mais hedônicos, como os sentimentos que derivam da posse do produto.

Os critérios de avaliação freqüentemente diferem em suas influências na seleção de produtos pelo consumidor, pois alguns critérios têm mais impacto do que outros para um mesmo consumidor. Da mesma forma, os consumidores podem diferir quanto à importância atribuída a cada critério de avaliação (ENGEL; BLACKWELL; MINIARD, I995). A importância de cada atributo refere-se à influência potencial que cada um dos atributos pode exercer durante o processo de comparação de produtos. Os atributos importantes (salientes) que realmente influenciam o processo de avaliação são chamados de atributos determinantes. Engel, Blackwell e Miniard (I995) citam os seguintes fatores influenciadores que afetam a saliência dos atributos no processo de avaliação de alternativas de produtos:

- influência situacional: os fatores situacionais (por exemplo, a ocasião de uso do produto) geralmente exercem uma grande influência na importância do critério de avaliação;

- $\quad$ semelhança das alternativas: decisões envolvendo alternativas não comparáveis podem exigir que o consumidor utilize critérios de avaliação mais abstratos, como necessidade, divertimento, status;

- motivação: a presença das motivações hedônica ou utilitária determinará o tipo de critério de avaliação provável de ser utilizado pelo consumidor;

- envolvimento: um número maior de critérios de avaliação será provavelmente utilizado no processo de decisão na medida em que o envolvimento do consumidor com a compra ou com o produto aumenta;

- conhecimento: consumidores bem informados terão informações sobre as dimensões guardadas na memória que serão úteis na comparação de alternativas. Essas informações são menos prováveis de existir na memória de consumidores novatos. Conseqüentemente, os novatos estarão muito mais suscetíveis às influências externas que tentam influenciar seus critérios de avaliação. Essa conceituação do país de origem como atributo do produto deriva do paradigma das dicas, "cue paradigm" no original em inglês. A palavra "cue", nesse sentido, significa dica ou indicador sobre um atributo. As dicas sobre atributos de produtos são importantes variáveis de marketing, que influenciam as decisões de compra de clientes potenciais. Vários estudos têm examinado o impacto potencial das dicas de produtos nas avaliações dos clientes acerca da qualidade dos produtos e nas subseqüentes intenções de compra (FORSYTHE; 
KIM; PETEE, I999). No contexto do efeito país de origem, este funciona como uma "dica" ou atributo extrínseco do produto, assim como preço, marca e garantia (AYROSA, 1998).

Como atributo extrínseco, o país de origem opõe-se a atributos intrínsecos, como potência, peso, composição, temperatura, durabilidade etc. Verifica-se, portanto, que os atributos intrínsecos estão diretamente relacionados às características do produto. Assim, uma mudança nesses atributos significa uma mudança substancial, até mesmo física, no produto. Por outro lado, uma mudança nos atributos extrínsecos não afeta de forma direta o produto final (AYROSA, I998). Pesquisas têm demonstrado que as indicações extrínsecas intangíveis são constantemente usadas pelos consumidores como indicadores substitutos quando faltam indicações intrínsecas ou quando estas são difíceis de avaliar (ZHANG, I997).

\section{FATORES MEDIADORES DO EFEITO PAÍS DE ORIGEM}

Enquanto parece haver um consenso sobre o fato de a imagem do país de origem exercer um impacto na avaliação dos produtos, existe ao mesmo tempo um debate constante sobre a magnitude desse efeito, particularmente na presença de outras informações intrínsecas e extrínsecas sobre o produto, e sobre os fatores ambientais e culturais que podem facilitar ou inibir a confiança no país de origem. Alguns desses fatores mediadores do efeito país de origem, ou seja, que afetam a importância dessa informação para o consumidor, são relacionados com as características do consumidor e com a categoria do produto.

As características do consumidor que podem influenciar o efeito país de origem são: educação e conservadorismo, idade e sexo, familiaridade com a marca, fluência na língua do país, quantidade de pistas sobre o produto, necessidade de cognição, motivação, grau de envolvimento e cultura. Com relação à educação e ao conservadorismo, os consumidores com menos educação e politicamente conservadores são mais propensos a desenvolver aversão a produtos estrangeiros (ANDERSON e CUNNINGHAM, I972).

A idade (SHIMP e SHARMA, I987) e o sexo (JOHANSSON; DOUGLAS; NONAKA, I985) do consumidor também provocam diferenças na receptividade a produtos estrangeiros: os consumidores mais velhos tendem a ter mais aversão a produtos estrangeiros. O sexo do consumidor também influencia a percepção da imagem "fabricado em" (made in), com as mulheres tendo um viés maior contra produtos estrangeiros e a favor de produtos nacionais (BALABANIS; MUELLER; MELEWAR, 2002). 
Com relação à familiaridade, quando os consumidores se confrontam com uma marca familiar, eles tendem a fazer avaliações sobre o produto de forma rápida e direta, sem muito esforço na busca de informações, pois estão familiarizados com os atributos da marca (BRUCKS, I985). Nessas situações, a busca e o processamento de informações não são necessários. Assim, parece razoável assumir que os consumidores que estão familiarizados com uma marca em particular podem desconsiderar ou ignorar o país de origem ou outras informações sobre atributos, na avaliação dessa marca (SCHAEFER, I997).

A fluência na língua do país de origem é mais um fator de influência, relacionado com o conhecimento que o consumidor possui acerca do país de origem do produto. Esse fator pode resultar em avaliações mais positivas do país por proporcionar acesso a fontes de informações adicionais fora do país do consumidor, e por facilitar o contato direto (BALABANIS; MUELLER; MELEWAR, 2002). O simples contato com um país, sem a habilidade de se comunicar com as pessoas, pode limitar seriamente o acesso às informações sobre o país e, conseqüentemente, pode afetar as percepções.

Com relação à quantidade de pistas sobre o produto, Chao e Rajendran (I993) afirmam que, quando o consumidor tem acesso a um número maior de pistas sobre o produto, a eficácia de uma pista em particular, como o país de origem, na influência das avaliações que um consumidor faz sobre um produto pode ser reduzida. Esse processo causaria uma diminuição do efeito país de origem, mas não o seu desaparecimento. Em seu estudo, Chao e Rajendran (I993) demonstram que os consumidores podem confiar na marca como um efeito país de origem implícito, substituindo as avaliações do produto, independentemente do fato de o produto ter sido realmente fabricado no país com o qual a marca pode estar fortemente associada.

O efeito país de origem pode ainda ser influenciado por uma diferença mais fundamental entre os consumidores: vontade e disponibilidade para processar informações (ZHANG, I997). Zhang (1997) defende a hipótese que o efeito de país de origem pode ser influenciado pelas diferenças individuais na necessidade de cognição dos consumidores. A necessidade de cognição é o prazer e a motivação do indivíduo para se engajar em um processamento cognitivo de informações que exige esforço de sua parte. O efeito país de origem é especialmente forte em indivíduos que não estão cognitivamente dispostos a avaliar os atributos dos produtos, e usam o país de origem como uma pista-resumo que pode afetar a avaliação sobre o produto. A qualidade da argumentação pode se tornar um importante determinante da atitude para indivíduos com alto grau de necessidade de cognição (ZHANG, I997). Para indivíduos com baixos níveis de necessidade de cognição, o país de origem (como indicação extrínseca), mais do que a qualidade da argumentação, pode se tornar um importante determinante da atitude. 
A motivação do consumidor é mais um fator que influencia o uso da informação sobre o país de origem. Sob condições de alta motivação, os consumidores estarão propensos a seguir um processamento detalhado da mensagem persuasiva, o qual envolve o exame atencioso dos argumentos relevantes para a mensagem (como informação sobre atributos). Em comparação, sob baixa motivação, um modo menos esforçado de processamento é esperado, e os consumidores provavelmente formarão seus julgamentos de uma forma cognitiva mais simples (GURHAN-CANLI e MAHESWARAN, 2000). Portanto, sob baixa (versus alta) motivação, os consumidores podem tentar formar seus julgamentos com um mínimo esforço, e o país de origem oferece uma base para fazerem isso (MAHESWARAN, I994).

Ao contrário, consumidores altamente motivados são menos propensos a usar atalhos cognitivos na formação de seus julgamentos. A informação do país de origem pode ser processada e considerada, porém mais como um dos atributos do produto do que como base geral para julgamento. Quando os consumidores utilizam o país de origem como base para julgamento em situações de baixa motivação, ou quando o objetivo do processamento cognitivo é avaliar o país de origem, eles direcionam a atenção para as informações acerca do país de origem do produto. Por outro lado, se os consumidores não se atêm ao país de origem, como no caso de alta motivação, ou quando o objetivo do processamento desvia a atenção das informações sobre o país de origem, qualquer evidência sobre o país de origem é menos provável de ser utilizada em seus julgamentos (GURHAN-CANLI e MAHESWARAN, 2000).

Com relação à influência da cultura no efeito país de origem, Guilhoto (200I) salienta que muitos dos atributos desejados pelos consumidores para um produto estão intimamente ligados à cultura na qual eles estão inseridos. Em seu trabalho, a autora destaca dois aspectos culturais que atuam diretamente na percepção dos consumidores sobre a influência do país de origem dos produtos. O primeiro deles é o quanto o país tem características mais individualistas ou mais coletivistas. De acordo com Canli e Maheswaran (2000), as pessoas que possuem uma formação mais individualista tendem a minimizar a importância das informações sobre o país de origem, priorizando a qualidade do produto. Por sua vez, os coletivistas apresentam uma propensão natural a enfatizar mais o grupo do que o indivíduo, tendendo a avaliar os produtos nacionais de uma forma mais favorável, independentemente de sua superioridade.

Para Guilhoto (200I), outro aspecto cultural importante para a verificação da influência do país de origem é o grau de etnocentrismo de uma cultura. O etnocentrismo pode ser definido como o modo pelo qual um grupo se considera referência, classificando os demais grupos com base em suas características. Para Shimp e Sharma (1987), quanto mais etnocentrista for o consumidor, mais 
ele tenderá a ver a compra de produtos estrangeiros como algo danoso porque, segundo a sua visão, seu consumo feriria a economia doméstica, levaria à perda de empregos e não seria patriótico.

As variáveis relacionadas com o tipo/categoria do produto também têm um papel no uso do país de origem como critério de seleção entre alternativas (PAPADOPOULOS e HESLOP, I993; PAPADOPOULOS, I993). Por exemplo, o país de origem é geralmente mais eficiente para produtos agrícolas do que para produtos manufaturados, dada a associação histórica entre produção e país de origem ou região de origem (AGRAWAL e KAMAKARA, I999). Além disso, o grau de envolvimento do consumidor para com produtos agrícolas é menor do que para com produtos manufaturados. Esse fato gera um efeito maior do país de origem na avaliação de produtos agrícolas pelos consumidores.

Para Papadopoulos e Heslop (I993) outras variáveis que afetam o uso do país de origem como critério de compra incluem: o nível de desenvolvimento do país de origem, as associações históricas entre o país de origem e certos produtos (por exemplo, a França possui associações históricas na produção de roupas e alimentos) e a força dessas imagens de país de origem com a categoria de produtos. Esse fato indica que as imagens do país de origem terão mais "legitimidade" em certas circunstâncias do que em outras.

Os gerentes devem, portanto, avaliar cuidadosamente a história das associações da categoria do produto com o país de origem antes de utilizarem essa variável para aumentar o conhecimento de seus produtos. Se um país possuir uma história de associação negativa entre país de origem e categoria de produto, poderá ser prejudicial utilizar o país de origem no programa de marca. Os gerentes devem também planejar os programas de país de origem no longo prazo, pois o país de origem possui menos importância quando os consumidores tornam-se mais familiarizados com os produtos (BEVERLAND, 2002).

De acordo com as evidências empíricas citadas por Bar Tal (I997), relações de conflito entre dois países podem levar à formação de imagens de países negativas, enquanto os relacionamentos cooperativos levam à formação de imagens de países positivas. As relações atuais entre dois países podem ser cooperativas, porém um histórico de relações conflituosas pode ainda influenciar fortemente a imagem do país. Por exemplo, um histórico de antagonismos, guerras, hostilidade, amizade ou cooperação entre dois países torna-se parte da memória coletiva e afeta as percepções das pessoas com relação ao outro país. O estudo de Balabanis, Mueller e Melewar (2002) demonstrou que, para fabricantes que lidam com países menos amigáveis com seu país, o melhor conselho é não utilizar o país de origem nas promoções do produto e nas embalagens. O oposto é verdadeiro quando os fabricantes estiverem lidando com países mais amigáveis. 
Até o momento, foram apresentadas as definições de imagem de um país e os fatores mediadores do efeito país de origem, salientando as condições em que o efeito é mais ou menos intenso. Verificou-se que o país de origem pode ser operacionalizado em diversas formas, e que um grande número de variáveis relacionadas com a empresa, consumidores, estratégia, histórico e produtos influencia a aplicabilidade de seu uso. Assim, o uso do país de origem depende de diferentes fatores contextuais, e a aplicabilidade do país de origem muda em resposta a mudanças no contexto. A seguir, são apresentados os conceitos relacionados à vantagem competitiva de uma empresa, para que possam ser traçadas considerações quanto ao uso da informação sobre o país de origem de produtos brasileiros como fonte de vantagem competitiva nos mercados externos.

\section{VANTAGEM COMPETITIVA}

O segundo termo central a ser definido neste trabalho é a vantagem competitiva. A criação e a renovação contínuas de novas fontes de vantagem competitiva são a rota mais segura para a lucratividade sustentada (DAY, I990). Para Hitt, Ireland e Hoskisson (I997), a base de uma vantagem competitiva é formada pelas diferenças nos recursos que uma empresa possui, com relação a seus concorrentes. Essa suposição deriva do modelo baseado em recursos, que assume que cada organização é uma coleção de recursos e capacidades únicos, que fornece a base para as suas estratégias e é a fonte primária de seus retornos. De acordo com esse modelo, as diferenças entre os desempenhos de diferentes empresas são direcionadas, primeiramente, pelos recursos e capacidades de cada empresa, e não pelas características estruturais da indústria (HITT; IRELAND; HOSKISSON, I997).

Segundo Hitt, Ireland e Hoskisson (1997), o modelo baseado em recursos também assume que, ao longo do tempo, as empresas adquirem diferentes recursos e desenvolvem capacidades únicas. Dessa forma, as empresas que competem em uma dada indústria podem não possuir os mesmos recursos e capacidades estrategicamente relevantes. Outra suposição do modelo é que pode não haver uma grande mobilidade entre os recursos de empresas diferentes. Essas diferenças nos recursos formam, assim, a base de uma vantagem competitiva.

A imagem do país de origem de um produto pode ser considerada um recurso intangível para uma empresa, em oposição aos recursos tangíveis, como recursos financeiros, físicos, humanos e organizacionais. Para Hitt, Ireland e Hoskisson (1997), como os recursos intangíveis são menos visíveis e mais difíceis para os concorrentes compreenderem, comprarem, imitarem ou substituírem, os gerentes preferem usá-los como fonte de capacidades e competências 
centrais. Os recursos tangíveis e intangíveis são uma parte crítica no processo de desenvolvimento de uma vantagem competitiva. Porém, nem todos os recursos e capacidades de uma empresa têm o potencial para se tornarem a base de uma vantagem competitiva. O potencial é realizado quando os recursos e as capacidades são valiosos, raros, difíceis de imitar, e não substituíveis.

As capacidades e os recursos superiores, em conjunto, representam a habilidade de uma empresa de fazer mais, ou melhor, (ou as duas coisas) do que os seus concorrentes. As superiores são as capacidades distintivas dos recursos humanos que os diferenciam da concorrência. Um dos benefícios advindos das capacidades superiores é a habilidade de desempenhar as funções individuais de uma forma mais eficaz do que outras empresas. Os recursos superiores, por sua vez, são condições mais tangíveis para a vantagem, que permitem que a empresa exercite as suas capacidades. Esses recursos podem residir na escala de produção, na localização, na amplitude da força de vendas e na cobertura da distribuição, na disponibilidade de linhas de montagem automatizadas ou na marca dos produtos (DAY e WENSLEY, I998).

Além das capacidades e dos recursos superiores, Aaker (I992) ainda acrescenta que onde a empresa compete (a seleção do mercado-alvo) e contra quem ela compete (a seleção dos concorrentes) são fatores importantes a serem considerados quando da criação de uma vantagem competitiva sustentável. Para esse autor, uma estratégia bem definida, suportada por recursos e capacidades, pode falhar por não funcionar no mercado. Assim, uma estratégia e seus recursos e capacidades subjacentes precisam envolver algo valioso para o mercado. Além disso, às vezes um recurso ou habilidade formará uma vantagem competitiva apenas quando determinado o conjunto adequado de concorrentes. Portanto, é vital avaliar se um concorrente ou grupo estratégico é fraco, adequado, ou forte, com relação aos recursos e capacidades. O objetivo é desenvolver uma estratégia que superará os concorrentes que não possuam pontos fortes em recursos e capacidades relevantes.

Para Day (1990), existem duas diferentes perspectivas a respeito de como avaliar uma possível vantagem competitiva: as avaliações centradas nos concorrentes e as centradas nos clientes. Nem todos os negócios optam por dominar uma forma ou outra, combinando os melhores aspectos de ambas. A importância da definição de uma perspectiva de compreensão da vantagem competitiva advém da simplificação de uma parte incontrolável do ambiente, guiando a escolha das informações a serem selecionadas e definindo a forma como serão filtradas e interpretadas.

As avaliações de vantagens centradas nos concorrentes são baseadas em comparações diretas, feitas pela gerência, com alguns concorrentes-alvo. Essa mentalidade é encontrada com maior freqüência em indústrias concentradas e 
intensivas de capital, em um mercado de crescimento lento e maturidade tecnológica. Nesse cenário, as empresas estão constantemente em busca de uma vantagem, com a ênfase de "vencer os concorrentes". Os clientes são considerados como os "prêmios" ganhos na vitória sobre os concorrentes (DAY e WENSLEY, I998).

Por outro lado, as avaliações de vantagens centradas nos clientes baseiam-se na satisfação relativa dentro dos segmentos e procuram identificar as ações necessárias para garantir novas vantagens. Essa orientação é mais evidente em indústrias fragmentadas em que há um grande número de concorrentes, cada um procurando demarcar uma posição distinta em um mercado altamente segmentado. As empresas participantes dessa mentalidade gastam relativamente pouco tempo observando os concorrentes e fazendo comparações com suas competências e seu desempenho, pois a ênfase está na qualidade das relações com os clientes (DAY, I990).

Day (I990) ainda acrescenta um terceiro tipo de avaliação de vantagens: as autocentradas. As empresas autocentradas verificam os melhoramentos, ano a ano, em índices operacionais importantes, a fim de avaliar seu desempenho. Em geral, existe uma forte orientação para o volume de vendas, sendo, portanto, o crescimento das vendas um indicador básico de desempenho competitivo. Uma crítica a essa mentalidade reside no fato de ser uma perspectiva voltada para dentro. Um negócio poderá suportar ou sobreviver a essa perspectiva somente se não possuir concorrentes diretos (devido a uma forte liderança tecnológica, ou a uma posição de mercado bem protegida), ou se todos os concorrentes agirem da mesma forma, coexistindo confortavelmente.

Cabe ressaltar que Day e Wensley (I998) acreditam que não existe apenas um significado para o termo "vantagem competitiva", na prática ou na literatura de marketing. As várias visões existentes, consideradas em conjunto, descrevem tanto o estado da vantagem quanto a forma em que foi obtida. Essa visão integrada é baseada em uma superioridade de posição e de desempenho, sendo uma conseqüência da superioridade relativa das capacidades e dos recursos utilizados pela empresa. Essas capacidades e recursos refletem o padrão dos investimentos passados a fim de melhorar a posição competitiva. Para esses autores, a sustentação dessa vantagem requer que o negócio estabeleça barreiras que tornam a imitação difícil. Como essas barreiras à imitação estão se erodindo de maneira contínua, a empresa necessita continuar a investir para sustentar ou melhorar a vantagem. Portanto, a criação e a sustentação de uma vantagem competitiva são o resultado de um processo cíclico. A seguir, é apresentada a forma de conversão de vantagens competitivas em estratégias competitivas para uma empresa. 


\section{CONVERSÃO DE VANTAGENS EM ESTRATÉGIAS COMPETITIVAS}

As capacidades e os recursos superiores representam as fontes de vantagem competitiva para uma empresa. De acordo com Day e Wensley (I998), o resultado do uso adequado dessas fontes de vantagem leva uma empresa a estabelecer uma posição de vantagem, análoga às barreiras de mobilidade competitivas que poderiam deter uma empresa a mudar a sua posição estratégica. Essas vantagens são melhor compreendidas no contexto de cadeia de valor atribuído a McKinsey, mas amplamente desenvolvida em uma ferramenta de negócios por Porter (DAY, I990).

Uma cadeia de valor primeiro classifica as atividades da empresa nas etapas necessárias para projetar, produzir, comercializar, entregar e prestar serviços referentes a um produto. Dando suporte a essas atividades específicas de criação de valor, encontram-se as atividades mais amplas do negócio, como compras, gestão de recursos humanos, desenvolvimento de tecnologias, assim como a infra-estrutura de sistemas e gestão que mantém a cadeia de valor unida. Somente as atividades que exercem um grande impacto na diferenciação e que representam uma grande proporção dos custos devem ser consideradas. A idéia básica de uma cadeia de valor lembra aos estrategistas que nenhuma atividade é sagrada na empresa. Isso significa que se alguma atividade puder ser desempenhada de forma mais eficaz ou eficiente por um fornecedor ou distribuidor (ou mesmo pelo cliente), então essa atividade deve ser eliminada.

As capacidades e os recursos superiores permitem às empresas trilhar um caminho para conquistar a liderança do mercado. Para Day (I990), os caminhos mais genéricos para sustentar a liderança de mercado são: diferenciação (por meio da qualidade e serviços superiores, relações mais próximas com os clientes ou respostas mais rápidas) e liderança nos custos baixos. Porém, independentemente de qual dos caminhos for escolhido, o esforço somente terá sucesso se for criado um valor significativo para o cliente. A escolha acerca do caminho para a liderança envolve um sólido processo de planejamento que estabeleça a necessidade de mudanças, gere alternativas significativas e consiga um consenso gerencial sobre a melhor fonte de vantagem para o negócio.

Além da liderança no custo total e da diferenciação, Porter (I986) apresenta outra abordagem estratégica genérica potencialmente bem-sucedida para superar as outras empresas em uma indústria: a estratégia de foco. Para o autor, a colocação em prática de qualquer uma dessas estratégias genéricas exige, em geral, comprometimento total de disposições organizacionais de apoio, que serão diluídas se existir mais de um alvo primário.

A seguir, são apresentadas as principais características das estratégias competitivas genéricas mencionadas: diferenciação, menor custo e foco. Em primeiro 
lugar, serão abordados os aspectos relativos à diferenciação. Um negócio é diferenciado quando certas atividades adicionadoras de valor são desempenhadas de modo que levam a uma superioridade percebida ao longo das dimensões que são valiosas para os clientes. Para que essas atividades sejam lucrativas, os clientes precisam estar dispostos a pagar um preço premium pelos benefícios, e esse premium precisa exceder os custos adicionais resultantes desse desempenho superior (DAY e WENSLEY, I998). Uma empresa e seus produtos podem ser diferenciados de uma forma favorável em um sem-número de maneiras: fornecer serviço superior, possuir uma marca forte, oferecer características inovadoras, oferecer qualidade superior nos produtos são algumas das rotas possíveis. Day (I990) fornece uma forma de apresentar a superioridade de valor, como pode ser verificado o gráfico I.

\section{GRÁFICO I}

\section{MAPEAMENTO DO VALOR}

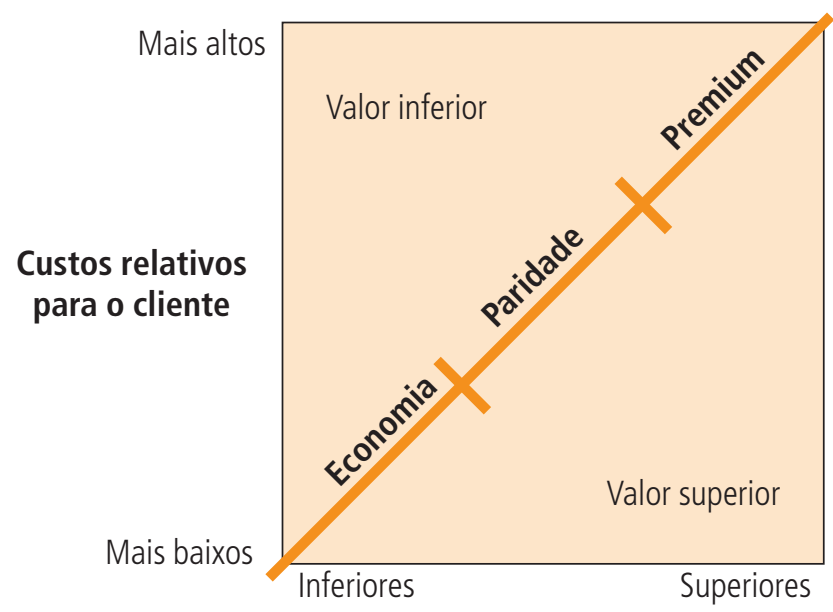

Benefícios relativos percebidos pelo cliente

Fonte: Adaptado de DAY, I990.

Segundo Day (I990), a maior parte dos negócios posiciona suas ofertas sobre a diagonal que vai da economia ao premium, precificando os seus produtos de forma que capturem o valor para o cliente que foi criado. Alguns concorrentes, todavia, ficam posicionados fora da diagonal (proposital ou acidentalmente). Aqueles que cobram preços médios por benefícios menores estão oferecendo um valor inferior, o que torna essa posição não segura no longo prazo. Para Day (I990), uma posição de valor "campeã" para os clientes é a de benefícios superiores por um preço médio. 
Porém, para a empresa, a posição mais lucrativa é sobre a diagonal do mapa de valor, na extremidade premium do mercado. Porter (I986) acredita que atingir a diferenciação pode, às vezes, tornar impossível a obtenção de uma alta parcela de mercado. Isso acontece devido ao fato de a estratégia em questão requerer um sentimento de exclusividade que é incompatível com essa alta parcela de mercado.

A segunda estratégia competitiva genérica é a baseada no menor custo. Uma vantagem de custo é obtida se a empresa consegue desempenhar a maioria das atividades com um custo menor do que a concorrência, enquanto oferece um produto semelhante. Segundo Porter (I986), essa estratégia tornou-se bastante comum nos anos 70 devido à popularização do conceito da curva de experiência. A liderança no custo exige a construção agressiva de instalações em escala eficiente, uma perseguição vigorosa de reduções de custo pela experiência, um controle rígido do custo e das despesas gerais e a minimização do custo, gerando intensa atenção administrativa ao controle dos custos.

Day (I990) destaca que a liderança de custos normalmente é atingida por empresas que oferecem produtos padronizados ou econômicos. Essa vantagem nos custos é obtida com operações em larga escala, permitindo a diluição dos custos indiretos, baixos custos de fabricação por meio da operação em áreas de baixos salários e pela disposição para investir em fábricas e equipamentos que proporcionem reduções de custos.

Para Porter (I986), atingir uma posição de custo total baixo quase sempre exige uma alta parcela de mercado relativa ou outras posições vantajosas, como acesso favorável às matérias-primas. Essa estratégia pode exigir também o projeto de produtos para simplificar a fabricação, a manutenção de uma vasta linha de produtos relacionados para diluir os custos e o atendimento de todos os principais grupos de clientes de modo a expandir o volume. Por outro lado, a implementação da estratégia de baixo custo pode exigir investimento pesado de capital em equipamento atualizado, fixação de preço agressiva e prejuízos iniciais para consolidar a parcela de mercado. Uma grande participação de mercado poderá permitir à empresa economias nas compras, reduzindo ainda mais os custos. Uma vez atingida, a posição de baixo custo proporciona margens altas que podem ser reinvestidas em novos equipamentos e instalações, de forma que mantenha a liderança no custo.

Segundo Day (I990), para que uma estratégia de valor tenha sucesso, o preço a mais que o cliente está disposto a pagar deve exceder os custos de fornecer o valor extra. Analogamente, uma estratégia de custos precisa oferecer um valor aceitável aos clientes, para que os preços cobrados fiquem próximos aos valores cobrados pela concorrência. Se a posição de baixo custo for conseguida por meio do sacrifício exagerado da qualidade do produto ou serviço, ou da eliminação de características consideradas vantajosas pelos clientes, a redução de preço exigida pelos clientes anulará a vantagem obtida nos custos. 
Finalmente, a terceira estratégia competitiva genérica é a baseada no foco. Segundo Porter (I986), a estratégia de foco consiste em enfocar um determinado grupo comprador, um segmento da linha de produtos ou um mercado geográfico. Verifica-se que, como a diferenciação, a estratégica de foco pode assumir diversas formas. Essa estratégia repousa na premissa de que a empresa é capaz de atender seu alvo estratégico estreito de forma mais eficaz ou eficiente do que os concorrentes que competem de um modo mais amplo no mercado. Conseqüentemente, a empresa atinge a diferenciação por satisfazer melhor as necessidades de seu alvo particular, ou custos mais baixos na obtenção desse alvo, ou ambos.

Mesmo que a estratégia de foco não atinja o custo mais baixo ou a diferenciação do ponto de vista do mercado como um todo, ela realmente atinge uma ou ambas as posições em relação ao seu estreito alvo estratégico. A estratégia de foco sempre implica alguma limitação na parcela total de mercado que pode ser atingida. Essa estratégia envolve necessariamente uma escolha entre a rentabilidade e o volume de vendas. As diferenças entre as três estratégias apresentadas encontram-se ilustradas no gráfico 2.

As três estratégias genéricas de Porter (I986) são métodos alternativos viáveis para lidar com as forças competitivas da indústria. Para esse autor, uma empresa que fica no meio-termo está em uma situação estratégica extremamente pobre. Isso acontece devido à baixa lucratividade esperada para essa empresa: ou ela perde os clientes de grandes volumes, que exigem preços baixos, ou deve renunciar a seus lucros para colocar seu negócio fora do alcance das empresas de baixo custo. Porém, essa empresa também perde negócios com altas margens para aquelas que atingiram um padrão de diferenciação global. Além disso, a empresa no meio-termo provavelmente também sofre de uma cultura empresarial indefinida e de um conjunto conflitante de arranjos organizacionais e sistemas de motivação. 
GRÁFICO 2

TRES ESTRATÉGIAS GENERICAS

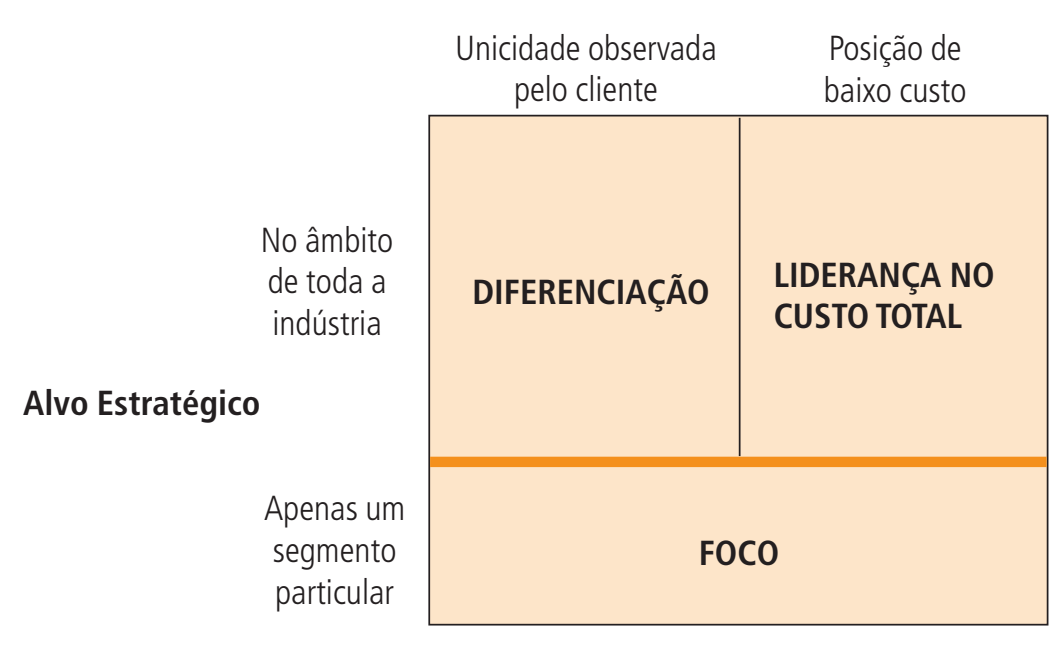

Fonte: PORTER, I986.

Para Porter (I986), a empresa na posição de meio-termo deve tomar uma decisão fundamental. Ou ela adota as medidas necessárias para alcançar a liderança (ou, ao menos, a paridade) de custo, acarretando investimentos agressivos para modernizar as instalações, ou ela deve orientar-se para um mercado determinado (foco) ou atingir alguma supremacia (diferenciação). A escolha entre essas opções está necessariamente baseada nas capacidades, nos recursos e nas limitações da empresa. A execução bem-sucedida de cada estratégia genérica requer recursos diferentes, diferentes virtudes, disposições organizacionais e estilo administrativo. Portanto, raramente uma empresa está ajustada para todas as três estratégias.

Aaker (I992) apresenta outras duas possíveis estratégias competitivas: a baseada na preempção e a baseada na sinergia. As estratégias de preempção são aquelas que empregam as vantagens do primeiro entrante no mercado, de forma que os concorrentes fiquem impedidos, ou dificultados, de copiar ou obter certos recursos ou capacidades. O movimento de preempção associado a vantagens competitivas sustentáveis pode surgir de três fontes: liderança tecnológica, preempção de ativos e custos de mudança de comprador. Além disso, ele pode ser direcionado ao sistema de fornecimento, ao produto, ao sistema de produção, aos clientes ou aos sistemas de distribuição e serviços.

Por sua vez, as estratégias de sinergia confiam na sinergia entre um negócio e outros negócios na mesma empresa. A sinergia entre unidades estratégicas de 
negócios pode fornecer uma vantagem competitiva realmente sustentável, pois esta é baseada nas características de uma empresa. Um concorrente teria que duplicar uma organização para poder capturar os recursos e as capacidades envolvidas. Sinergia significa que o todo é maior do que a soma das partes. Nesse contexto, isso significa que duas unidades estratégicas de negócio operando juntas serão superiores às mesmas duas unidades estratégicas de negócio operando de forma independente. Em geral, a sinergia será causada devido a pontos em comum em duas operações como: distribuição, imagem e seu impacto no mercado, uso ou aplicação, vendas ou esforço de propaganda, uso de instalações, esforço de pesquisa e desenvolvimento e custos operacionais (AAKER, I992).

Day e Wensley (I998) sugerem que as capacidades e os recursos que exercem a maior alavancagem nas vantagens competitivas e no desempenho futuro sejam identificados, para que sejam obtidas melhorias de desempenho com o mínimo de despesas. Em seguida, devem-se alocar os recursos seletivamente entre essas fontes alavancadas. Esses autores criticam a literatura de marketing, por esta não dar atenção à conversão de vantagens em resultados superiores. Em seu artigo, Day e Wensley (1998) procuram preencher essa lacuna, fornecendo uma estrutura necessária para melhor delinear as realidades da formulação de estratégia competitiva, apresentada no Desenho I. As explicações da estrutura encontram-se a seguir.

\section{DESENHO I}

\section{UMA ESTRUTURA PARA AVALIAR A VANTAGEM COMPETITIVA}
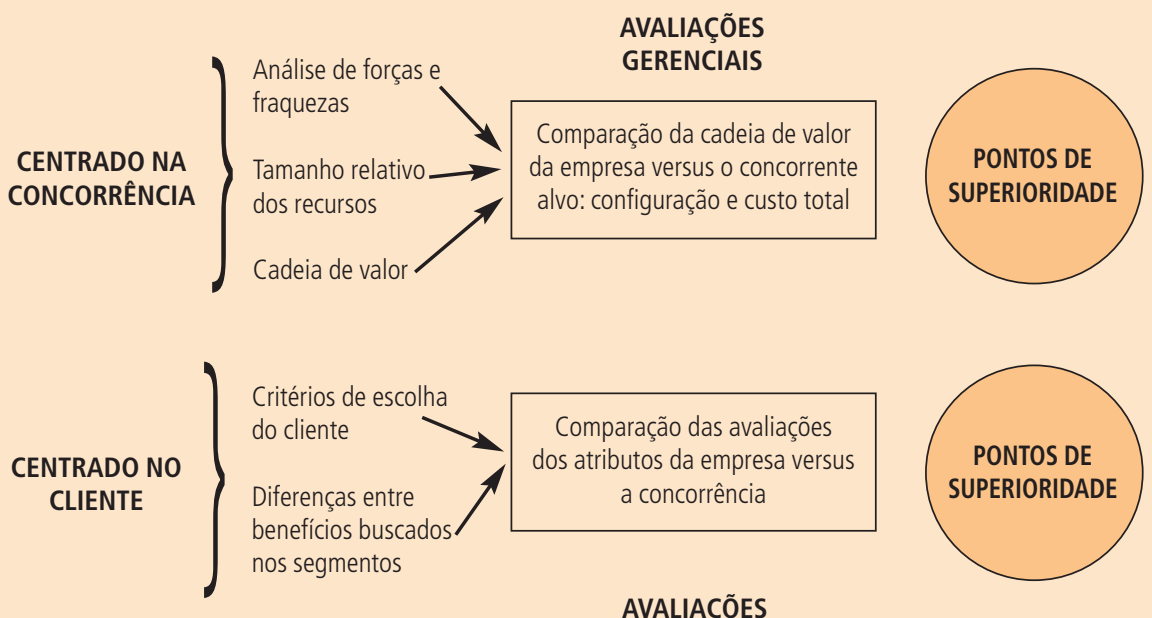

DOS CLIENTES 
As capacidades e os recursos superiores não são automaticamente convertidos em vantagens, nem existe uma recompensa certa derivada de desempenhos superiores de custo ou de diferenciação. Ambas as conversões são mediadas em conjunto pelas escolhas estratégicas, incluindo os objetivos, o tempo de entrada no mercado e a qualidade das táticas e da implementação. A utilidade prática advinda dos esforços de avaliar a vantagem vem da identificação acurada dos recursos e capacidades que exercem a maior alavancagem no desempenho. Esses são os fatores-chave de sucesso que precisam ser administrados obsessivamente para assegurar a eficácia competitiva no longo prazo. Essa estrutura descreve o desempenho de um negócio em relação aos seus concorrentes. $\mathrm{O}$ desempenho absoluto também depende da atratividade geral do mercado, determinada pela estrutura e comportamento da concorrência.

Com relação à eficácia de uma vantagem competitiva, Aaker (I992) apresenta as seguintes condições para que uma vantagem competitiva seja considerada eficaz: ser suportada por recursos e capacidades, ser empregada em uma arena competitiva que contenha segmentos que valorizarão a estratégia, ser empregada contra concorrentes que não podem facilmente alcançar ou neutralizar a vantagem, ser suficientemente substancial para fazer diferença e ser sustentável em face das mudanças ambientais e das ações dos concorrentes.

Hitt, Ireland e Hoskisson (I997) explicam que uma vantagem competitiva sustentável é alcançada apenas quando os concorrentes da empresa tiverem tentado duplicar, sem sucesso, os benefícios de sua estratégia ou quando os concorrentes não tiverem confiança suficiente para tentar imitar essa empresa. Isso significa que as capacidades da empresa devem ser valiosas, raras, custosas de imitar e não substituíveis. As capacidades que não satisfizerem esses critérios não são consideradas competências centrais e, por isso, não servem de base para uma vantagem competitiva sustentável.

\section{CONCLUSÕES}

\subsection{IMAGEM DO BRASIL: UMA FONTE DE VANTAGEM COMPETITIVA?}

O presente trabalho investiga o uso da informação acerca do país de origem de produtos brasileiros como fonte de vantagem competitiva nos mercados externos. Para que uma empresa tenha uma vantagem competitiva, é necessária a posse de uma característica única que não pode ser adquirida ou copiada pelos seus concorrentes. O país de origem de um produto apresenta tal característica. Por isso, teoricamente, a imagem do Brasil pode vir a ser utilizada como forma 
de diferenciação da oferta de produtos brasileiros comercializados no exterior, atuando como uma vantagem competitiva, de modo que a leve a uma superioridade percebida para os clientes. A imagem do Brasil poderia ser considerada um recurso intangível para uma empresa brasileira exportadora, sendo a base para a formação da estratégia de diferenciação dos produtos brasileiros. Para tanto, a imagem do Brasil deveria possuir as características que tornam os recursos uma fonte de vantagem competitiva: ser valiosa, rara, difícil de imitar e não substituível. Além disso, os consumidores dos mercados externos deveriam estar dispostos a pagar um preço premium pelo fato de esse produto ser brasileiro, para que a estratégia de diferenciação fosse bem-sucedida.

Para usar o país de origem como um recurso que leva a uma vantagem competitiva, deve-se considerar que o efeito país de origem pode ser positivo quando o país for associado com os melhores padrões técnicos de qualidade e inovação. A imagem do país de origem pode vir a ser usada nas estratégias competitivas das empresas para posicionar seus produtos, devido à presença da crescente competição e padronização dos produtos como resultado da globalização. Isso ocorre particularmente com a presença crescente dos governos nacionais e das associações de comércio na arena global, utilizando a imagem do país na promoção de seus produtores (PAPADOPOULOS e HESLOP, I993).

Porém, um importante empecilho para a estratégia de uso da informação sobre o país de origem de produtos brasileiros como vantagem competitiva nos mercados externos é apontado por Fonseca (2003). Esse autor acredita que, apesar da heterogeneidade do parque industrial brasileiro, e da diversidade e complexidade dos seus produtos e serviços, muitos deles com nível de competitividade externa, e em setores altamente dinâmicos do ponto de vista tecnológico, a imagem do Brasil no exterior é principalmente associada a algumas habilidades esportivas (sobretudo ao futebol) ou criativas, relacionadas, por exemplo, à sua expressividade e musicalidade, que tem seu ponto máximo no carnaval.

Dessa forma, quase nenhum significado ou importância é atribuído ao Brasil enquanto provedor de itens de maior conteúdo tecnológico, ou de qualidade reconhecida no exterior. Como a imagem de um país influencia as expectativas de preço dos produtos por parte do consumidor - quanto pior a imagem, maior a expectativa de descontos no preço, comparando com produtos idênticos de outros países com imagens mais fortes (NEBENZAHL e JAFFE, I996) -, os consumidores de mercados externos devem esperar que os produtos brasileiros tenham preços mais baixos. Esse fato impõe uma barreira à utilização da imagem do Brasil como sendo um recurso para vantagem competitiva, levando à estratégia de diferenciação, já que esta acarreta a cobrança de um preço premium pelos produtos.

O conhecimento dos consumidores de mercados externos com relação ao Brasil, e, sobretudo com relação ao nível de qualidade de sua produção interna, 
ainda se mostra bastante restrito e tendencioso, desconhecendo-se aspectos freqüentemente vistos na economia interna, vinculados à relevância, qualidade e aprimoramento tecnológico. Para Fonseca (2003), duas são, aparentemente, as motivações principais para esse pouco conhecimento ou percepção equivocada: a pouca exposição ao público externo dos bens e serviços brasileiros e o fato de o Brasil pouco se apresentar nos meios de comunicação, sendo geralmente mostrado por instituições ou pelas mídias externas que não têm conhecimento acerca de aspectos importantes da realidade brasileira, ou que a enxergam sob ótica fora de foco (realçando fatos negativos, tais como corrupção, agressões ao meio ambiente, desrespeito aos direitos humanos e desigualdades sociais).

Esse autor não considera outras possíveis causas para tal percepção acerca da qualidade dos produtos brasileiros. Em primeiro lugar, existe uma tendência natural dos meios de comunicação de explorarem as más notícias em detrimentos das boas. Em segundo lugar, o próprio governo brasileiro possui uma parcela de responsabilidade, por não possuir um programa de relações públicas voltado para a divulgação de notícias e feitos das empresas brasileiras para o mercado externo.

Com relação às estratégias a serem perseguidas pelas empresas que desejam utilizar a imagem de seu país como fonte de vantagem competitiva, Guilhoto (200I) salienta que ter uma imagem de país favorável torna recomendável que as empresas enfatizem a frase made in em seus produtos. Os elementos do composto de marketing devem ser emoldurados por essa imagem positiva, para permitir a adoção de preços premium, a realização de distribuição exclusiva e a utilização de propagandas e promoções que reforcem esse aspecto. Ou seja, nesse caso, quando a imagem do país for positiva, a informação acerca do país de origem poderia ser uma fonte de vantagem competitiva para as empresas exportadoras.

Porém, no caso do Brasil, como as empresas atuam em um país cuja imagem é desfavorável no exterior, elas deveriam adotar estratégias que minimizem esse impacto negativo. Entre essas estratégias, destacam-se a promoção de uma marca mais forte, o estabelecimento de um preço que vai ao encontro do valor que o consumidor atribui ao produto e a busca do estabelecimento de parcerias na cadeia de suprimentos para montar um processo de distribuição suficientemente forte e bem estruturado que ajude a neutralizar os aspectos negativos. Isso significa que, se não houver uma melhoria na imagem do país, a empresa deve buscar outras formas de obtenção de vantagem, como no caso da construção de uma marca forte (não relacionada ao país de origem).

Portanto, em resposta à pergunta da pesquisa “a informação acerca do país de origem de produtos brasileiros pode ser utilizada como fonte de vantagem competitiva nos mercados externos?”, deve-se concluir que essa não é, no momento, uma estratégia viável para as empresas brasileiras. Para que as empresas possam desenvolver um plano estratégico destacando o país de origem em suas 
formas de comunicação, é necessário, em primeiro lugar, que ocorra a melhoria de imagem do Brasil no exterior. Esse esforço de longo prazo compete ao governo brasileiro, que precisa desempenhar um papel fundamental nesse processo, comunicando ao mundo aspectos positivos da economia e cultura brasileiras, destacando-se seu grau de sofisticação em alguns setores, seu nível tecnológico, design elaborado e cuidados com o meio ambiente.

Enquanto isso não ocorre, uma sugestão oferecida para as empresas brasileiras seria o desenvolvimento de pesquisas para constatar a imagem atual de seus produtos. Isso feito, o resultado deveria ser considerado como imperativo de mercado, e ações para minimizar os possíveis efeitos negativos seriam tomadas, de acordo com as sugestões de Guilhoto (200I) apresentadas anteriormente.

O presente estudo foi caracterizado por ser de cunho teórico, empregando a utilização da análise de dados secundários para responder à pergunta da pesquisa. Dessa forma, uma limitação da pesquisa deve-se à sua própria natureza exploratória. Estudos futuros poderiam investigar empiricamente a questão proposta, por meio de entrevistas com especialistas em exportação e com gerentes de empresas que adotam o país de origem em suas estratégias de comunicação nos mercados externos, para compreender as opções estratégicas dessas empresas exportadoras.

\section{REFERÊNCIAS}

AAKER, D. A. Strategic market management. Berkeley: John Wiley \& Sons, I992.

AGRAWAL, J.; KAMAKARA, W. A. Country of origin: a competitive advantage. International Journal of Research in Marketing, n. I6, p. 255-267, I999.

ANDERSON, W. T.; CUNNINGHAM, W. H. Gauging foreign product promotion. Journal of Advertising Research, p. 29-34, feb. I972.

ASSAEL, H. Consumer behavior and marketing action. Boston: PWS-KENT, I992.

AYROSA, E. A. T. Imagem de país: uma escala para avaliar atitudes relativas a países. In: XXII Encontro Anual da ANPAD, ı998, Foz do Iguaçu. Anais..., Foz do Iguaçu, I998. CD-ROM.

.Some notes on the development of research on country-of-origin effects. Arché Internacional, Rio de Janeiro, ano IX (26), 2000.

BAKER, M. J.; BALLINGTON, L. Country of origin as a source of competitive advantage. Journal of Strategic Marketing, n. IO, p. I57-I68, 2002.

BALABANIS, G.; MUELLER, R.; MELEWAR, T.C. The human values' lenses of country of origin images. International Marketing Review, London, I9 (6), p. 582-610, 2002.

BAR TAL, D. Formation and change of ethnic and national stereotypes: an integrative model. International Journal of Intercultural Relations, 2I (4), p. 49I-523, I997.

BEVERLAND, M. Using country of origin in strategy: the importance of context and strategic action. Journal of Brand Management, London, Io (2), p. I47-I67, nov. 2002. 
BRUCKS, M. The effects of product class knowledge on information search behaviour. Journal of Consumer Research, Gainesville, p. I-I6, I2 june I985.

CANLI, Z. G.; MAHESWARAN, D. Cultural variations in country of origin effects. Journal of Marketing Research, Chicago: American Marketing Association, p. 309-317, aug. 2000.

CHAO, P.; RAJENDRAN, K. N. Consumer profiles and perceptions: country-of-origin effects. International Marketing Review, London, Io (2), p. 22-39, I993.

DAY, G. S. Estratégia voltada para o mercado: processos para a criação de valor dirigidos ao cliente. Rio de Janeiro: Record, I990.

DAY, G. S.; WENSLEY, R. Assessing advantage: a framework for diagnosing competitive superiority. Journal of Marketing, Nova York, n. 52, p. I-20, apr. I998.

ENGEL, J. F.; BLACKWELL, R. D.; MINIARD, P. W. Consumer behavior. 8. ed. Orlando: The Dryden Press, I995.

FONSECA, R. G. A importância da melhoria da imagem como instrumento de agregação de valor às exportações brasileiras. Export News, set. 2003. Disponível em: <http://www.exportnews.com.br/artigos/aa28.htm>. Acesso em: 16 set. 2003.

FORSYTHE, S.; KIM, J.O.; PETEE, T. Product cue usage in two asian markets: a cross-cultural comparison. Asia Pacific Journal of Management. Special Issue: Marketing in the Asia Pacific, I6 (2), aug. I999.

GUILHOTO, L. de F. M. A influência do país de origem na percepção do consumidor sobre a qualidade dos produtos. Caderno de Pesquisas em Administração, São Paulo, o8 (4), out./dez. 200 I.

GURHAN-CANLI, Z.; MAHESWARAN, D. Determinants of country-of-origin evaluations. Journal of Consumer Research, Gainesville, 27 (I), p. 96-Io8, jun. 2000.

HAN, C. M.; TERPSTRA, V. Country-of-origin effects for uni-national bi-national products. Journal of International Business Studies, n. I9, p. 235-55, summer I988.

HESLOP, L. A.; PAPADOPOULOS, N. But who knows where or when: reflections on the images of countries and their products. In: PAPADOPOULOS, N.; HESLOP, L. A. Product-country images: impact and role in international marketing. Londres: Haworth Press, I993.

HITT, M. A.; IRELAND, R. D.; HOSKISSON, R. E. Strategic management: competitiveness and globalization. 2. ed. West Publishing Company, I997.

JOHANSSON, J. K., DOUGLAS, S. P.; NONAKA, I. Assessing the impact of country of origin on product evaluations: a new methodological perspective. Journal of Marketing Research, n. 22, p. 388-96, nov. 1985 .

KOTLER, P. Administração de marketing: análise, planejamento, implementação e controle. 4. ed. São Paulo: Atlas, I995.

KOTLER, P.; GERTNER, D. Marca-país: ativo estratégico para alavancar o crescimento. HSM Management, n. 44, ano 8, vol. 3, p. 6I-65, mai./jun. 2004 .

MAHESWARAN, D. Country-of-Origin as a stereotype: effects of consumer expertise and attribute strength on product evaluations. Journal of Consumer Research, Gainesville, 2I (2), p. 354-365, sept. I994.

MCDANIEL, C.; GATES, R. Contemporary marketing research. Saint Paul: West Publishing Company, I996.

NAGASHIMA, A. A comparison of Japanese and U.S. attitudes towards foreign products. Journal of Marketing, n. 34, p. 68-74, I970. 
NEBENZAHL, I. D.; JAFFE, E. D. Measuring the joint effect of brand and country image in consumer evaluation of global products. International Marketing Review, I3 (4), I996.

PAPADOPOULOS, N. What product and country images are and are not. In: PAPADOPOULOS, N.; HESLOP, L. A. Product-country images: impact and role in international marketing. Londres: Haworth Press, I993.

PORTER, M. E. Estratégia competitiva: técnicas para análise de indústrias e da concorrência. Rio de Janeiro: Campus, I986.

SCHIFFMAN, L. G.; KANUK, L. L. Consumer behavior. Prentice Hall, I997. 672p.

SCHAEFER, A. Consumer knowledge and country of origin effects. European Journal of Marketing, Bradford, 3I (I), p. 56-72, I997.

SHIMP, T. A.; SHARMA, S. Consumer ethnocentrism: construction and validation of the CETSCALE. Journal of Marketing Research, p. 280-90, aug. I987.

SKAGGS, R.; FALK, C.; ALMONTE, J.; CARDENAS, M. Product-country images and international food marketing: relationships and research needs. Agribusiness (I986-I998). New York: I2 (6), p. 593-6oi, nov./dec. I996.

VERLEGH, P. W. J.; STEENKAMP, J.-B.E.M. A review and meta-analysis of country-of-origin research. Journal of Economic Psychology, n. 20, p. 521-546, I999.

ZHANG, Y. Country-of-origin effect: the moderating function of individual difference in information processing. International Marketing Review, Londres, I4 (4), p. 266-287, I997.

TR A MITAÇ $\tilde{A} O$

Recebido em 20/08/2004

Aprovado em 28/10/2004 